International Journal of Instruction

e-ISSN: 1308-1470 • www.e-iji.net

Article submission code:

20210531194322

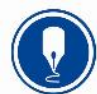

January $2022 \bullet$ Vol.15, No.1

p-ISSN: 1694-609X

pp. 1045-1064

Received: 31/05/2021

Revision: 03/09/2021
Accepted: 27/09/2021

OnlineFirst: 21/12/2021

\title{
Employment the Word Cloud in Brainstorming via the Web and Its Effectiveness in Developing the Design Thinking Skill
}

\section{Osamah Mohamad Ameen Ahmad Aldalalah}

Dr., Taibah University - Faculty of Education - Department of Educational

Technologies, Saudi Arabia, odalalah@taibahu.edu.sa

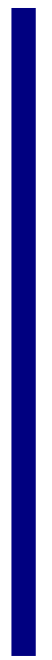

The purpose of this study was to investigate the effectiveness of using word clouds in brainstorming on developing design thinking skills through the web environment among Taibah University students in Saudi Arabia, and the degree of design thinking skills among students. The lesson of E-learning course was developed in two different modes, brainstorming via the web and virtual classes. Quasi experimental factorial design was adopted in this research. The independent variables were the two modes of courseware (the mode brainstorming through a word cloud, and the second mode virtual classes). The dependent variables were the design thinking skills. The study sample consisted of 72 students and were randomly (simple random sample) selected from ten classrooms. Descriptive and inferential statistics were conducted to analyse the collected data through the SPSS software. Analyses of covariance (MANCOVA) were performed to examine the main effects of the independent variables (Brainstorming) on the dependent variables (Design thinking skills). The findings of this study showed that students using the brainstorming via the web mode performed significantly better than those in the virtual classes mode. And that the students have a moderate degree of design thinking.

Keywords: e- brainstorming, virtual classes, word cloud, design thinking, thinking skills

\section{INTRODUCTION}

The use of technology in the educational process is inevitable. This requires training students and teachers to use it and trying to make it a method of learning that assists the learner and helps him in his studies, as the use of technological innovations in the educational process provides the learner with high knowledge interestingly and enjoys facilitating their learning process. These technical innovations include visual stimuli that have a great impact in facilitating and simplifying the introduction and presentation of information attractive and interesting (Santyasa, Agustini \& Pratiwi, 2021).

Visual stimuli are elements of design variables within digital educational content (Aldalalah, 2021). These stimuli work to attract the learner's attention, to the specific content, thus attracting his attention and directing his awareness towards the important

Citation: Aldalalah, O. M. A. A. (2022). Employment the word cloud in brainstorming via the web and its effectiveness in developing the design thinking skill. International Journal of Instruction, 15(1), 1045-1064. https://doi.org/10.29333/iji.2022.15159a 
elements in the educational content (Awwaf \& Zaidan, 2020). Further, visual stimuli are used to enhance the written content by highlighting and emphasizing its elements, hence the role of the word cloud which establishes the vision of the complete picture of the educational material and shows the role of educational methods and their interrelationship with other technology; for instance, the strategy of e-brainstorming (Aldalalah \& Ababneh, 2015 Aldalalah \& fong, 2010).

This study differed from other studies in terms of the presentation of the e-learning course through word-cloud-based brainstorming, Also, most of the studies relied on design thinking in building different teaching methods and in different topics, while this study relied on web-based brainstorming in developing students' design thinking skills in the e-learning course.

\section{Word cloud}

A word cloud is defined as collecting keywords to describe the content of a predefined educational material that appears randomly in the form of a cloud so that each word within this cloud has a size and color related to the degree of importance of that word (Le, \& Lauw, 2016). Furthermore, the most important words take a distinctive color and a larger size, and the importance of the word is inferred in terms of the number of repetitions on a specific educational topic, i.e., the word appears, according to its weight according to its frequency or location in the text (Atenstaedt, 2017). The word cloud is a textual, visual representation of specific content by displaying unique words that provide the user with a high ability to get an impression on the content of the topic presented through key words (Hui-Li, 2016). It does not need any human explanations or clarifications, which makes it easy to be employed for large groups that in turn participate in expressing a specific idea or a specific document by inserting exciting words that are semantic for these documents and ideas, which makes the words in the cloud an ideal entry point to search for a specific word in the document (Jin, 2017). The word cloud is used in various educational materials, It is highly effective in the classroom, as it works to develop learners' abilities in multiple thinking skills and in accessing abstract concepts because of the educational environment created by this method of teaching that depends mainly on motivating students (Denoyelles \& Foster, 2015). Learners share by proposing and incorporating a large number of new and innovative ideas by using keywords within the program or application used in the production of the cloud to guide them towards a specific concept or idea of organizing their ideas within the classroom (Bromley, 2013).

Further, this method can be used in the introduction to the lesson to link learners' ideas with previous learning and to move to current learning in addition to the high flexibility in using it in the strategey of brainstorming in education related to presenting many ideas to identify some of them to solve an educational problem in one of the specific educational topics (Volkert, 2018). The word cloud is an ideal way to encourage exploration and knowledge of concepts or topics through keywords that abbreviate a lot of texts which in turn help students to learn about concepts and link this knowledge and concepts with students' previous learning (lemke, 2016). The word cloud can be used in 
the classroom to activate the classroom activities by adding keywords belonging to a specific idea to reach the ideas from these keywords, in addition to the possibility of using them in some posters and visual stimuli to convey an idea to the learners; it is a good way to extract ideas based on the interestingly presented keywords (Zan \& Zan, 2015).

The word cloud can be an effective means to motivate students and develop their ability to think and understand some abstract concepts. Further, this method can be used in the introduction to the lesson to link learners' ideas with previous learning and move to current learning because of its high flexibility when used in brainstorming strategy in education; where learners present the largest possible amount of innovative ideas and proposals through using the words in the cloud, to adopt some of them to solve an educational problem in one of the specific educational topics by organizing lesson ideas and directing students to a specific result or concept (Alonso, et al, 2018); as students have a high ability to generate ideas in the form of semantic words through interaction between students with each other and with the teacher actively leading to a change in thinking, and encouraging the study of the educational content objectively and logically. This facilitates the building of meaning for this content. Additionally, the students 'thinking processes are shedding light on through their extensive participation. They likely find the task interesting, exciting and stimulating through the internet discussion (Cavender \& Medico, 2018).

Despite these advantages of the word cloud, it should be dealt with and presented clearly so that all students can understand the required task and analyse it collectively, as analysing the word cloud is a challenge and it should be so.

\section{E-brainstorming}

E-brainstorming is known as an electronic educational method that uses several electronic programs and applications through which the teacher presents a specific educational problem or situation and asks students to work on solving this problem by proposing many ideas electronically through these applications or programs and then evaluating those ideas that were proposed and choosing the best one to solve the problem at hand (Abdel Samie, 2015). Muheisen (2016) stresses on the use of technological innovations to allow all students to participate in generating as many ideas as possible on a specific topic. Yunis (2017) believes that it is a method aimed at students' participation and stimulating their interaction to put forward ideas on a specific topic to be discussed within an electronic environment. Further, e-brainstorming is one of the e-learning strategies, during which a specific problem or topic is presented and discussed to reach the largest number of ideas and choose the best of them (Abu Mutlaq, 2018).

E-brainstorming has many advantages, as it is one of the appropriate strategies for large groups of learners in terms of the possibility of proposing multiple ideas and generating them simultaneously with ease of communication, speed in presenting ideas freely and not feeling hesitant (Al-Zahrani, 2016); in addition to student participation in evaluating the findings of the discussions of the proposed sessions leading to creating an active 
learning environment that allows learners to research and learn (AlMutairi, 2015). Further, e-brainstorming affects in increasing student achievement as well as creating an educational atmosphere that focuses on higher thinking skills such as analyzing, applying and installing information and interpreting it because e-brainstorming includes various sessions that allow students to propose various solutions; accept opinions and provide an opportunity for discussion and dialogue, and give various solutions. This increases the comprehension of what the learner sees by providing an opportunity to think, retrieve previous knowledge about the problem or the presented topic, and then providing space for discussion and interaction, and accepting opinions and proposals, which had a great impact on learning (Al-Saqaria \& Al-Salmi, 2019). E-brainstorming provides a positive learning environment dominated by a feeling of closeness and familiarity between the teacher and students, and at the same time it reduces the state of anxiety and tension associated with brainstorming sessions, which often comes from anxiety about evaluation, fear of making mistakes, or proposing strange ideas (Debbies, Alshshaeir \& Rbye, 2018).

In e-brainstorming strategy, all ideas must be accepted and recorded electronically with an emphasis not to criticize any of the ideas to reach convincing solutions to the problem at hand, as e-brainstorming is the result of a combination of traditional strategies (brainstorming) and one of the e-learning models that have proven successful in the educational process as a whole (Hidayanti, Rochintaniawati \& Agustin, 2018). Abu Mutlaq (2018) and Yunus (2017) both indicate that e-brainstorming is divided into: computer-assisted brainstorming through the use of specially designed programs to record some students' proposed ideas and then put them on a large screen in front of all students for discussion, dialogue and access to adopting the best solutions. The other section is brainstorming via the Internet through social media tools and applications, where everyone has the opportunity to participate and discuss in putting forward ideas.

In this study, the researcher used online brainstorming, which makes education more motivating and increases motivation among students by posing ideas at any time and place. The researcher also adopted the answer garden application.

The findings of many studies have confirmed the effectiveness of e-brainstorming in the educational process, due to the time and effort it saves, as communication takes place via the Internet with the group members, which helps to remove the psychological pressure that some group members may feel by attending face to face. Online screen dealing is better. In addition to its ability to record conversations electronically and then recover them at any time and quickly when needed, even if they are groups with a large number of participants in finding solutions to the problem (Al-Saqria, \& Al-Salmi, 2020; Attia, 2019; Debbies, 2019).

\section{Design thinking}

Design thinking is considered a model and methodology for finding early and creative solutions for the people of society. Many institutions are looking to implement it, especially educational, administrative, and economic institutions because of its great impact on solving problems and facing the challenges facing institutions ( $\mathrm{Li}$, et al, 
2018). Design thinking affects all services provided to community members by providing services that facilitate their lives in all areas by solving their problems, meeting their needs, achieving their desires, and finding the best solutions to make their lives easier. It aims to make the targeted community members more satisfied, happy, psycho-social, and stable (Al-Zubaidi \& Bani Khalaf, 2020). If there is no problem to be solved by design thinking, design thinking improves productivity, enhances loyalty, and develops products and services for members of society with profit or non-profit goals (Dosi, Rosati \& Vignoli, 2018). Therefore, design thinking is a very important model that must be taught to students because it provides practical, operational thinking skills that help them be creative and capable of preparing them for a bright future (Collins, 2019).

Design thinking is one of the most satisfactory and stable psychological and social methods due to its ability to fulfill the desires and needs of the target population through its ability to explore complex problems and solve them, find the best innovative solutions for them, popularize these innovative solutions and enhance belonging, productivity and performance through the development of services and products for the target (Euro-net, et al, 2018 ). Design thinking is also a useful methodology adopted by designers based on knowledge of the different processes and methods to achieve the target's desire to solve the problems they face, so there is an urgent need to teach students design thinking, as it provides them with practicing thinking skills in a practical, operational way that develops their imagination and creativity to prepare them for the future (Cook \& Bush, 2018).

Owda (2019) defines it as a process which seeks to understand the user and redefine problems in an attempt to identify strategies and alternative solutions that may not be immediately apparent. At the same time, design thinking provides a list of solutions for problems. Hammam (2018) defined design thinking as a way of thinking that works to enhance students' ability to empathize with the problem, identify this problem, be creative in generating ideas and solutions, build and design a model to solve the problem, and finally test the model.

Many studies (Owda, 2019; Elsbach \& Stigliani, 2018; Cook \& Bush, 2018; Ewina, Luckb, Chughc \& Jarvisa, 2017) have indicated stages that design thinking passes through several stages: First: Empathising, which is defined as the ability of the individual to possess high levels of imagination by placing himself in the place of the target or user trying to reach the problems, challenges, and difficulties that surround him, and then analyse these problems, understand them accurately and be familiarized with his desires. This stage helps to know how the targeted individuals understand and interact with their problems by following some tasks, such as role-play and coexistence with the individuals targeted by the design. The aim is to define their needs and then analyse their characteristics to adopt their point of view in understanding the problem to reach a deep understanding of the problem and circumstances. Second: determining or defining the problem At this stage, what was reached in the previous stage to determine the type of problem that will be solved is analysed and classified provided that this problem relates to the largest possible number of targeted individuals. Further, at this 
stage, the problem is explicitly formulated relying on the findings of the reincarnation stage and then determining the actual needs of the targeted to determine the dimensions of this problem. Third: Generating ideas and visualizing the solution: Here comes the stage of solving the problem after carefully identifying it as well as proposing the largest number of solutions and ideas, whether ordinary ideas and solutions or innovative and creative ideas desirable and applicable from the beneficiary's point of view; then studying these proposals and solutions according to their feasibility. This skill can be determined by presenting preliminary proposals for a solution in light of the data, proposing more than one alternative and weighing between them; then making a scientific decision in choosing among the alternatives presented and finally taking the opinions of the beneficiaries in the comparison between the alternatives. Fourth: Building the initial models: After reaching the best executable of these solutions, study how it will be translated into a testable product or service through a preliminary model that can be modified and developed to verify the effectiveness of the solutions that were nominated from the idea generation stage. At this stage, precise steps are presented to reach a preliminary design that is also accurate according to solution visualization findings with a detailed explanation of this model. Fifth: the final stage is testing and evaluation of the model: at this stage, the plan becomes ready for implementation, i.e. transferring the solution to the ground through the experience of the target individuals of the product or service for the monitoring and evaluation process and obtaining feedback to know the ease of use and its need for modification. This stage includes the benefit from the feedback on the presented form, reviewing the defect and deficiency in the model, if any, and working on correcting the model in light of the data, developments, and feedback. Design thinking can be employed in the classroom by identifying a problem related to its idea of the school curriculum, and then students must generate formed ideas, conceptualizations, implement them, then test and redesign to ensure the success of the design.

Based on the previous literature and by comparing previous studies in the literature it was found that this study agrees with the other studies by dealing with E-brainstorming, but it differed in terms of the method of brainstorming, where the E-brainstorming was presented in this study by employing the word cloud, This study also differed from others in terms of the way the word cloud is used. Finally, this study differed from others in terms of the dependent variable, which is design thinking and the development of its skills among students of the e-learning course, while in other studies it was employed as an independent variable in building various educational programs.

The Problem of the Study

Design thinking plays an effective role in solving problems and developing creative thinking skills, as it is student-dependent learning skills, which require the teacher to think like a designer and not just a teacher planning the lesson; rather adapting the educational process to suit teachers specifically, as he looks at the available environment to create an enabling environment for the learner to achieve the highest possible benefit. The current research problem has crystallized in the detection and development of design thinking among students of Taibah University through the use of one of the 
technological innovations of e-brainstorming due to the scarcity of studies that dealt with the development of design thinking in this category, especially using the word cloud, and thus researchers have found that students need to develop their design thinking because the usual methods of teaching may not provide students with sufficient skills to design and implement procedures that contribute to solving life problems. In light of the above, the problem can be presented and addressed by answering the following questions:

- What is the level of design thinking skills among Taibah University students?.

- What is the effectiveness of e-brainstorming by relying on the word cloud in developing the design thinking skills of Taibah University students?.

Importance of the study

The importance of the study appears through the following aspects:

This study comes in response to the recommendations of previous studies that called for the use of e-brainstorming in developing thinking skills. Further, this study can contribute to providing faculty members and those of similar rank in educational colleges with the ability to find solutions to problems in education by designing digital contents based on e-brainstorming as well as providing them with methods that take into account the different characteristics and individual differences among students by adopting an word cloud in e-brainstorming. This study may enrich theoretical literature with studies based on adopting the word cloud in e-brainstorming in developing design thinking skills. Moreover, the importance of this study comes as it provides a theoretical framework for some concepts (e-brainstorming, word cloud, design thinking), which is scarce in general. The development of design thinking is one of the modern goals in the educational process by converting the knowledge acquired by the student into executive skills that solve many of the problems facing him, especially in e-learning. Ebrainstorming that depends on the word cloud can help students with the skills of design thinking to suggest solutions to the problem before them, such as e-learning and discussion, to reach the best possible solutions.

\section{Operational Definitions}

Word cloud: It is a set of randomly organized words or with presets that can be inserted into ready-made templates with the ability to choose different colors and fonts that revolve around the subject of e-learning. Sometimes it allows displaying the most frequent words in a certain text; therefore, the more frequent the word, the larger it appears in the word cloud. See figure 1 

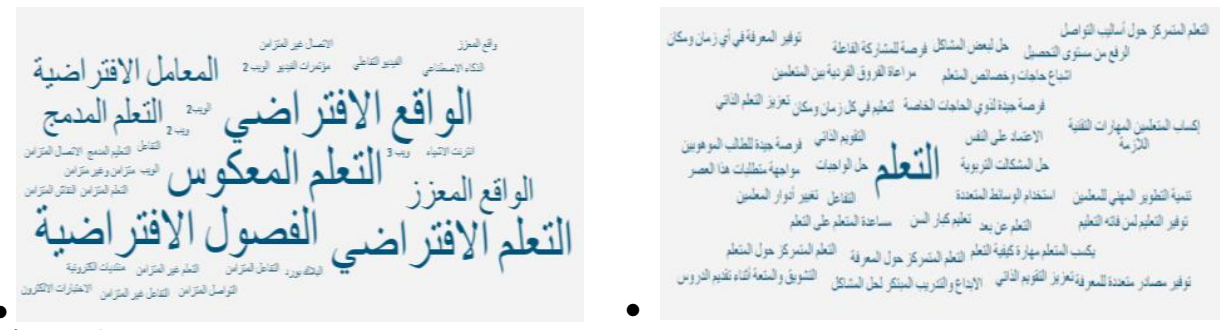

Figure 1

E-brainstorming through a word cloud

E-brainstorming: It is one of the e-learning strategies that depend on generating the largest possible number of diverse and innovative ideas by employing the word cloud and presenting them to students for discussion and collective dialogue electronically to reach an appropriate solution to the problem at hand.

Design Thinking: It is an effective model for facing challenges, solving problems, developing and improving the e-learning course by finding innovative and creative nontraditional solutions centred on the student and based on understanding his needs in the e-learning course.

The limitation of the study

Human limits: The study is applied to students of the College of Education in the elearning course.

Time limits: The study was applied in the second semester of the year 2020-2021.

Spatial limits: This study was applied at Taibah University in Al-Madinah AlMunawwarah in Saudi Arabia.

Objective limits: This study dealt with the topic of brainstorming in the e-learning course for students of the College of Education.

\section{METHOD}

\section{Study population and sample}

The study population consisted of all students registered in the e-learning course at the College of Education at Taibah University (Saudi Arabia) in the first semester of the academic year (2020/2021), The study was applied to the students of this university, as the researcher works in it as a faculty member, in addition to the cooperation of the university administration and the provision of facilities for the implementation of the study. The university also adopts many modern teaching methods

The sample of the study consisted of (72) male students, It was distributed into two groups randomly the first group consisting of 35 students, studied through electronic brainstorming through a word cloud, and the second group consisted of 37 students, studied through virtual classes. 
The experience included the following topics in the e-learning course (e-learning, elearning patterns, virtual learning, blended learning, flipped learning, e-courses via the web).

A pre-test that measures before the beginning of the study. To examine the equality between groups table (1), the MANOVA procedure was used results have been shown that there is no significant difference in the pre test scores between groups. This means that groups of students have the same level of knowledge in design thinking skills.

Table 1

Equal study groups in design thinking skills

\begin{tabular}{llll}
\hline$\bullet$ & Domains & $\bullet$ & Sig \\
\hline$\bullet$ & Empathising & $\bullet$ & .278 \\
\hline$\bullet$ & Defining & $\bullet$ & .444 \\
\hline$\bullet$ & Ideating & $\bullet$ & .784 \\
\hline$\bullet$ & Prototyping & $\bullet$ & .210 \\
\hline$\bullet$ & Testing & $\bullet$ & .743 \\
\hline$\bullet$ & Overall scale & $\bullet$ & .558 \\
\hline
\end{tabular}

\section{Research Design}

Since the current study has focused on studying the effectiveness of electronic brainstorming through the word cloud in developing the design thinking skills of Taibah University students in the e-learning course, the researcher used two types of research method, Analytical method to determine the list of students' design thinking skills, and the quasi-experimental method was also used to compare the effectiveness of different teaching mode.

\section{Research Instrument}

To identify the students' design thinking skills At Taibah University, the researcher developed the inventory of design thinking skills depending on on his experience, relevant literature review (Owda, 2019; Dosi, Rosati \& Vignoli, 2018; Ahmad, 2018; Euro-net, et al, 2018; Chesson, 2017). The inventory of design thinking skills measured 5 domains: the empathising measured by 12 items; defining measured by 9 items, ideating measured by 11 items, prototyping measured by 13 items, and testing measured by 13 items. The students' receive a score of 3 for Always, 2 for Often, 1 for Sometimes, and 0 for Never for positive items, a score of 0 for Always, 1 for Often, 2 for Sometimes, and 3 for Never for negative items.

\section{Research Instrument Validity}

Validity consists of two different aspects that is face and content validity. Face validity refers to the degree to which a design thinking scale appears to measure what it claims to measure, while content validity refers to the degree to which a scale measures an intended content area. Face validity and content validity were judged by a panel of experts. The design thinking scale was evaluated during the development of the research study. The feedback and comments received from the panel of experts were employed to 
establish the necessary clarifications, changes, and modifications before and after piloting the study.

\section{Correlation coefficient}

To extract the indications of the validity of the design thinking scale, the paragraphs correlation coefficients were extracted for the scale, where the study was applied to an exploratory sample consisting of (15) students who were outside the study sample, as the correlation coefficient here represents the significance of the validity of each paragraph of the scale and the total score As shown in the table (2).

Table 2

Correlation coefficients between the design thinking skills scale items and domains, and between the scale items and the overall scale

\begin{tabular}{|c|c|c|c|c|c|c|c|c|c|c|c|c|c|c|}
\hline \multirow{2}{*}{\multicolumn{2}{|c|}{$\begin{array}{c}\text { Testing } \\
\text { Correlation } \\
\text { Coefficient }\end{array}$}} & \multirow{3}{*}{ I } & \multirow{2}{*}{\multicolumn{2}{|c|}{$\begin{array}{l}\text { Prototyping } \\
\text { Correlation } \\
\text { Coefficient } \\
\end{array}$}} & \multirow{3}{*}{ I } & \multirow{2}{*}{\multicolumn{2}{|c|}{$\begin{array}{c}\text { Ideating } \\
\text { Correlation } \\
\text { Coefficient } \\
\end{array}$}} & \multirow{3}{*}{ I } & \multirow{2}{*}{\multicolumn{2}{|c|}{$\begin{array}{c}\text { Defining } \\
\text { Correlation } \\
\text { Coefficient } \\
\end{array}$}} & \multirow{3}{*}{ I } & \multirow{2}{*}{\multicolumn{2}{|c|}{$\begin{array}{l}\text { Empathising } \\
\text { Correlation } \\
\text { Coefficient }\end{array}$}} & \multirow{3}{*}{ I } \\
\hline & & & & & & & & & & & & & & \\
\hline D & $\mathrm{S}$ & & D & $S$ & & D & $S$ & & D & $S$ & & D & $S$ & \\
\hline 0.64 & 0.91 & 46 & 0.86 & 0.87 & 33 & 0.68 & 0.75 & 22 & 0.79 & 0.72 & 13 & 0.90 & 0.89 & 1 \\
\hline 0.81 & 0.92 & 47 & 0.88 & 0.78 & 34 & 0.87 & 0.91 & 23 & 0.69 & 0.80 & 14 & 0.75 & 0.71 & 2 \\
\hline 0.89 & 0.85 & 48 & 0.81 & 0.71 & 35 & 0.90 & 0.92 & 24 & 0.71 & 0.76 & 15 & 0.89 & 0.91 & 3 \\
\hline 0.86 & 0.62 & 49 & 0.86 & 0.91 & 36 & 0.91 & 0.82 & 25 & 0.84 & 0.91 & 16 & 0.76 & 0.67 & 4 \\
\hline 0.82 & 0.72 & 50 & 0.91 & 0.72 & 37 & 0.66 & 0.86 & 26 & 0.93 & 0.72 & 17 & 0.73 & 0.83 & 5 \\
\hline 0.87 & 0.91 & 51 & 0.87 & 0.91 & 38 & 0.68 & 0.85 & 27 & 0.84 & 0.88 & 18 & 0.74 & 0.78 & 6 \\
\hline 0.81 & 0.88 & 52 & 0.90 & 0.65 & 39 & 0.88 & 0.79 & 28 & 0.89 & 0.65 & 19 & 0.64 & 0.76 & 7 \\
\hline 0.79 & 0.82 & 53 & 0.89 & 0.84 & 40 & 0.91 & 0.62 & 29 & 0.83 & 0.84 & 20 & 0.81 & 0,87 & 8 \\
\hline 0.82 & 0.83 & 54 & 0.67 & 0.79 & 41 & 0.66 & 0.76 & 30 & 0.85 & 0.79 & 21 & 0.89 & 0.81 & 9 \\
\hline 0.73 & 0.66 & 55 & 0.68 & 0.75 & 42 & 0.84 & 0.89 & 31 & & & & 0.86 & 0.79 & 10 \\
\hline 0.74 & 0.87 & 56 & 0.79 & 0.78 & 43 & 0.92 & 0.73 & 32 & & & & 0.82 & 0.82 & 11 \\
\hline 0.78 & 0.67 & 57 & 0.76 & 0.60 & 44 & & & & & & & 0.81 & 0.64 & 12 \\
\hline 0.73 & 0.71 & 58 & 0.81 & 0.85 & 45 & & & & & & & & & \\
\hline
\end{tabular}

Table (2) shows the statistical significance and the value of the correlation coefficient for all items in the design thinking scale with the domains and with the total score of the overall scale. The correlation coefficients ranged between the items and the domains (0.64 - 0.93), and the correlation coefficients ranged between the items and the overall score $(0.60-0.92)$, which are acceptable for the purposes of the study. 


\section{Research Instrument reliability}

The reliability is the degree to which a test consistently measures whatever it is measuring. A reliability coefficient helps in evaluating the consistency of the score created. The pilot study consisted of 15 students from the population of the study but were not included in the actual study. The researchers used Test-Retest to check the reliability of the instrument. The reliability coefficient of this instrument (The Arabic version) was computed by the implementation of Cronbach Alpha as shown in the table (3)

\section{Table 3}

Test-Retest reliability for design thinking scale

\begin{tabular}{llll}
\hline$\bullet$ & Domains & $\bullet$ & Sig \\
\hline$\bullet$ & Empathising & $\bullet$ & .84 \\
\hline$\bullet$ & Defining & $\bullet$ & .87 \\
\hline$\bullet$ & Ideating & $\bullet$ & .73 \\
\hline$\bullet$ & Prototyping & $\bullet$ & .85 \\
\hline$\bullet$ & Testing & $\bullet$ & .81 \\
\hline$\bullet$ & Overall scale & $\bullet$ & .82 \\
\hline
\end{tabular}

Thus, the design thinking scale in its final form consists of 58 items distributed into five Dimensions.

\section{FINDINGS}

The first question: What is the level of design thinking skills among Taibah University students?

To answer this question design thinking skills of the students was divided into three levels: Low, Medium and High. The levels are identified based on the following equation:

$$
Z=\frac{\text { Highest Mark }- \text { Lowest Mark }}{\text { Nnumber of Levels }}
$$

$Z=$ The difference between a level and the other.

$$
L=\text { Low }, \quad M=\text { Medium, } \quad H=\text { high }
$$

$L($ range $)=\left[\boldsymbol{L}_{\min }-\boldsymbol{L}_{\min }+Z\right] . M($ range $)=\left(\boldsymbol{L}_{\min }+Z-\boldsymbol{L}_{\min }+2 Z\right] . H($ range $)=\left(\boldsymbol{L}_{\min }+2 Z-\right.$

$$
\left.\boldsymbol{H}_{\min }\right] \text {. }
$$

Highest Mark $=163$, Lowest Mark $=80$, Number of Levels $=3$

$$
Z=\frac{163-80}{3}=27.66
$$

$\mathrm{L}($ range $)=[80-107] . \mathrm{M}($ range $)=(108-136] . \mathrm{H}($ range $)=(137-163]$

The average grades of the students were scored on the design thinking scale (126), This indicates that the students have a moderate degree of design thinking. 
The second question: Will students using the E-brainstorming mode attain significantly higher post test score in design thinking skills than students using virtual classes mode?

In order to answer this question, the means and standard deviations were extracted as shown in Table (4)

Table 4

Post-test scores in design thinking skills of students in various treatment groups

\begin{tabular}{llccc}
\hline Design Thinking Skills & Treatment Groups & Mean & Std. Deviation & $\mathrm{N}$ \\
\hline Empathising & E-brainstorming & 26.3143 & 4.92157 & 35 \\
& Virtual Classes & 22.2432 & 4.29732 & 37 \\
& Total & 24.2222 & 5.01609 & 72 \\
\hline Defining & E-brainstorming & 23.6000 & 3.29170 & 35 \\
& Virtual Classes & 18.5135 & 5.50061 & 37 \\
& Total & 20.9861 & 5.20426 & 72 \\
\hline Ideating & E-brainstorming & 27.0286 & 4.56641 & 35 \\
& Virtual Classes & 21.8649 & 4.33437 & 37 \\
& Total & 24.3750 & 5.12502 & 72 \\
\hline Prototyping & E-brainstorming & 31.0571 & 5.35198 & 35 \\
& Virtual Classes & 24.4865 & 4.95323 & 37 \\
& Total & 27.6806 & 6.09046 & 72 \\
\hline Testing & E-brainstorming & 31.2857 & 4.84204 & 35 \\
& Virtual Classes & 27.0811 & 7.85061 & 37 \\
& Total & 29.1250 & 6.85244 & 72 \\
\hline Overall scale & E-brainstorming & 139.2857 & 9.56578 & 35 \\
& Virtual Classes & 114.1892 & 12.69698 & 37 \\
& Total & 126.3889 & 16.88533 & 72 \\
\hline
\end{tabular}

From Table (4) it can be seen that that there is an apparent variation in the means and standard deviations of students 'responses to the design thinking scale. To identify the significance of the statistical differences between the arithmetic means, (MANCOVA) was used as summarized in Table (5)

Table 5

MANCOVA of the post-test scores in design thinking skills of students in various treatment groups

\begin{tabular}{lllllll}
\hline Source & Dependent Variable & Type III Sum of Squares & df & Mean Square & F & Sig. \\
\hline & Empathising & 343.978 & 1 & 343.978 & 28.039 & .000 \\
\cline { 2 - 7 } & Defining & 381.972 & 1 & 381.972 & 24.770 & .000 \\
\cline { 2 - 7 } $\begin{array}{l}\text { Treatment } \\
\text { Groups }\end{array}$ & Ideating & 435.776 & 1 & 435.776 & 28.627 & .000 \\
\cline { 2 - 7 } & Prototyping & 845.544 & 1 & 845.544 & 47.742 & .000 \\
\cline { 2 - 7 } & Testing & 262.824 & 1 & 262.824 & 7.551 & .008 \\
\hline & Overall scale & 10869.331 & 1 & 10869.331 & 122.489 & .000 \\
\hline
\end{tabular}

In order to know the effect on the effectiveness of electronic brainstorming on the development of design thinking skills, the researcher calculated the ETA Square $\eta^{2}$ 
The ETA square value is interpreted according to the following distribution:

The value of the ETA square $\left(\eta^{2}\right)$ is interpreted according to the following division:

From $\left(0.01 \leq \eta^{2}<0.06\right)$ the effect size is minimal.

From $\left(0.06 \leq \eta^{2}<0.14\right)$ the effect size is moderate.

From $\left(0.14 \leq \eta^{2}\right)$ the size of the effect is large.

Table 6

The results of the ETA square $\left(\eta^{2}\right)$ for the effectiveness of e-brainstorming in developing design thinking skills

\begin{tabular}{llll}
\hline$\bullet$ & Variables & $\bullet$ & $\eta^{2}$ \\
\hline$\bullet$ & Empathising & $\bullet$ & .167 \\
\hline$\bullet$ & Defining & $\bullet$ & .242 \\
\hline$\bullet$ & Ideating & $\bullet$ & .257 \\
\hline$\bullet$ & Prototyping & $\bullet$ & .295 \\
\hline$\bullet$ & Testing & $\bullet$ & .095 \\
\hline$\bullet$ & Overall scale & $\bullet$ & .560 \\
\hline
\end{tabular}

The $\left(\boldsymbol{\eta}^{2}\right)$ results, as shown in Table (6), E-brainstorming through the word cloud has an impact on developing design thinking skills among Taibah University students

\section{DISCUSSION}

The results showed that the level of design thinking among students who studied through electronic brainstorming was moderately, Where the mean e grades of the students were scored on the design thinking scale (126).

This result is attributed to what brainstorming provides through the web, which works to organize and reshape concepts through the search for knowledge and linking concepts with each other, which is reflected in the learner's focus and increased awareness of the concepts.

Also, this result is due to the fact that the e-brainstorming environment through virtual classrooms helped students to integrate into an interactive educational environment that raised their design thinking skills because it is distinguished by its ability to choose the best means for each stage of design thinking, increase the percentage of practicing live activities within the virtual classroom which gave opportunities for individual and group work, and increased the percentage of interaction between the teacher and students and students among themselves; and between educational content and external learning resources, in addition to interaction with the word cloud application. All of this created a stimulating, enjoyable and enriching learning environment for students, worked to remove boredom and increased activity, and thus raised design thinking skills. This study agreed with the study of Al-Saqria, \& Al-Salmi ( 2020); Attia (2019); Debbies (2019) and Hammam (2018).

Also, the results showed that the average grades of the students in the first experimental group, which were studied through e-brainstorming using the word cloud in virtual 
curiosity, were higher than the students who studied through the second experimental group, studied through presentations in the virtual classes.

The results have been shown that there is an apparent variation in the means and standard deviations of students 'responses to the design thinking scale and its domains. The values, $p=0.000$ showed a significant difference between the post-test scores of students with different method of teaching through brainstorming via the Web. This finding is attributed to the displaying the content of the e-learning course through ebrainstorming across the classroom based on the word cloud provided multiple attractions that depend on the visual stimuli represented in the keywords that appear on the screen in the form of an word cloud, which helped the quality of the resulting work and the ease of doing it because it contains elements of excitement and instigation. Further, it contributed to increasing the concentration, interaction and participation of students in proposing solutions, dialogue and discussion about them, which stimulated their motivation to learn. This had the effect of acquiring design thinking skills rapidly and accurately with less effort. This is what the word cloud presented about the effect of integrating the visual multimedia with the educational position on the students' understanding and perception of the e-learning course. It allowed interaction through their answers and share with them about everything that was presented through the word cloud application and helped provide various stimuli, as well as provided reinforcement and direct feedback. Additionally, it provided the opportunity for students to reach answers to many questions and problems that the methods and techniques of teaching through virtual classes did not allow to answer and solve by communicating with the teacher; further, it assisted them in putting forward several solutions that helped them raise and improve their level of knowledge and skills, as it provides flexibility and interactivity in dealing with content in a way that suits their needs as the educational environment through e-brainstorming is an enjoyable and encouraging environment for learning, and it helps students focus and work on solving obstacles and problems in a short time.

This finding can also be traced back to the fact that students were engaged in a large number of sessions that contained various activities; some of which dealt with one topic from several directions, such as taking it from a hypothetical or an analytical point of view, through the environment created by e-brainstorming through the word cloud to form a positive learning environment, dominated by a feeling of familiarity and closeness between the teacher and the students. At the same time, it reduced the tension and anxiety associated with brainstorming sessions, which often stemmed from the fear of evaluation and falling into error, or declaring what is going on in the mind sometimes of strange questions and ideas about scientific topics as e-brainstorming allows the student the freedom to produce and generate ideas. This reduces social anxiety; however, it does not prevent benefitting from the opinions and ideas of others, as well as increasing the production of ideas presented, as the case of the strategy of ebrainstorming.

In the stage of sympathy and empathy, e-brainstorming based on the word cloud allowed students to learn about the problem they are suffering from through discussion and 
dialogue, accept opinions, analyze information, and interpret it as this educational atmosphere is dominated by their character and application. This helped them empathize and embrace individuals who suffer from the problems presented, understand their point of view, and think about the effect of this problem for students.

As for the stage of defining or deciding the problem, e-brainstorming provided a free environment for learning. Furthermore, the activities included in the lessons carried provided an opportunity to research get acquainted with, and think about the presented issues through the keywords presented in the form of a word cloud, and to evoke the background knowledge about the presented issue; allowing students to discuss, interact, and analyse what has been reached in determining the problem that most students suffer from in the e-learning course. In the stage of generating ideas and visualizing a solution, e-brainstorming helped students create an atmosphere of comfort in proposing and discussing many ideas as well as expressing opinions without restrictions or fear; whether these ideas were compatible with other groups or not, accepting the opinions of others, and not criticizing ideas, and welcoming all the ideas raised about the problem. This aroused the enthusiasm of all students to participate freely by proposing multiple ideas in a safe environment in which there is no punishment or mockery of their ideas leading to encouraging them to integrate, participate and interact with each other to reach the ideal solution to the problem at hand.

As for the stage of building the prototypes: the first design is applied before reaching the final design, it is important for the next stages and it must be worked on to be an effective model to achieve satisfaction by students in the e-learning course because of its ability to solve their problems and obtain direct feedback because, in e-brainstorming, everyone knows that this model or design is a preliminary product that may contain weaknesses and unexpected findings that may need to be modified before the final product; hence, there may be suggestions or incorrect solutions that need to be canceled or deleted from the prototype. Therefore, when designing a prototype, you are trying to learn and get to know the product, so the focus is shifted to an opportunity to learn; eventually, the word cloud worked to provide opportunities for all students to participate in the creation of the prototype and comment on it freely.

The final stage is testing and evaluating the model: the students of the e-learning course was tested for the final model, and the e-brainstorming contributed to the students' participation in evaluating the findings of the discussions and sessions on the final product by introducing them to the word cloud application that enhanced their understanding of the e-learning course. Further, the course was presented interestingly and attractively that aroused students' interest in learning, developed self-learning, and made them the focus of the educational process. This increased their motivation towards learning, each according to his capabilities or aptitudes, and provided opportunities for practice and training leading to increased attention, focus, and understanding of the topics they studied and provided immediate feedback and direct reinforcement to make them feel the achievement and worked to establish the correct information on them. Further, this finding explains that the students, during their learning of the e-learning course through the e-brainstorming strategy based on the word cloud allowing them to 
learn about several exercises that helped raise and improve their level of knowledge and skills because of the flexibility and interactivity it provides in dealing with content in the manner that suits their needs.

In the end, the e-brainstorming method based on the word cloud that has distinctive tools, including conversations and direct responses, provided an opportunity to exchange experiences, discuss and benefit from them, along with an opportunity to express opinions and put forward ideas freely without restrictions, build on the ideas of others, and prepare a final report on the cognitive aspect related to thinking skills. The design is in addition to the self-evaluation, where the level of performance was continuously improving among the students. This study agreed with the study of AlZubaidi, and Bani Khalaf (2020); Hammam (2018); Cook and Bush (2018).

\section{RECOMMENDATIONS AND CONCLUSIONS}

This study found that the use of electronic brainstorming led to the development of design thinking skills among students of the e-learning course, to a medium degree. The study also found that the use of the word cloud in brainstorming via the web treatment mode helped students perform significantly better in learning e-learning course topics. It gives support to the effect of word cloud on the learning. In short, the study strongly indicated that a word cloud in brainstorming via the web was effective in promoting better learning.

In light of the results, the researcher recommends the following:

- Paying attention to e-brainstorming that relies on the word cloud because of its great impact on developing design thinking skills for their role in linking the cognitive side with the applied side.

- Working on introducing e-brainstorming that depends on the word cloud within the teaching methods applied in universities.

- Employing the list of design thinking skills that the researcher reached in the teaching process.

- The necessity of guiding and training faculty members in universities to design and use electronic brainstorming in education, because of its significant impact on improving achievement and developing thinking skills.

- Preparing training courses and workshops for faculty members and students in various disciplines on how to employ electronic brainstorming and design thinking in education.

- Making new studies dealing with larger samples and different topics about electronic brainstorming, design thinking and word clouds.

- Doing new studies in electronic brainstorming that include different thinking skills.

- Doing new studies on the employment of word clouds in classroom interaction. 


\section{REFERENCES}

Abdel Samie, H. (2015). The effectiveness of the different size of the participation groups in electronic brainstorming to develop thinking skills among educational technology students. Studies in university education, 30, $551-593$. https://drgawdat.edutech-portal.net/archives/14599

Abu Mutlaq, D. (2018). The effectiveness of employing electronic brainstorming in developing the skills of conceptual understanding in technology and electronic communication skills among female eleventh graders. Unpublished MA thesis, Islamic University of Gaza. https://library.iugaza.edu.ps/thesis/124518.pdf

Aldalalah, O. \& Ababneh, Z. (2015). Standards of Multimedia Graphic Design in Education. Journal of Education and Practice, 17(6), 102 - 111. https://files.eric.ed.gov/fulltext/EJ1079860.pdf

Aldalalah, O. (2021). The Effectiveness of Infographic via Interactive Smart Board on enhancing Creative Thinking: A Cognitive Load Perspective. International Journal of Instruction, 14(1), 345-364. DOI:10.29333/iji.2021.14120a

Aldalalah, O. Ababneh, Z. Bawaneh, A \& Alzubi, W. (2019). Effect of Augmented Reality and Simulation on the Achievement of Mathematics and Visual Thinking among students. International journal of emerging technologies in learning, 18(14), 164-185. https://doi.org/10.3991/ijet.v14i18.10748.

Aldalalah, O \& fong, S. (2010). Effect of Computer-Based Instructional Design among Internals-Externals: A Cognitive Load Perspective. European Journal of Social Sciences. 14(1), 164-182. https://www.researchgate.net/publication/287311838_Effects_of_computerbased_instructional_designs_among_internals-externals_A_cognitive_load_perspective

AlMutairi, A. (2015). The Effect of Using Brainstorming Strategy in Developing Creative Problem Solving Skills among Male Students in Kuwait: A Field Study on Saud Al-Kharji School in Kuwait City. Journal of Education and Practice, 6(3), 136145. https://files.eric.ed.gov/fulltext/EJ1083780.pdf.

Alonso, F., Fernández, V., Gómez, J. , Rodríguez, M., Pérez, C \& Mata, D. (2018). Word Clouds as a Learning Analytic Tool for the Cooperative e-Learning Platform NeuroK. In Proceedings of the 10th International Conference on Computer Supported Education, 2, 508-513. DOI:10.5220/0006816505080513

Al-Saqria, R \& Al- Salmi, M. (2020). The impact of using electronic brainstorming strategy in a blended learning environment on grade-eleven female students' in developing achievement motivation in islamic education. International Journal of Educational \& Psychological Studies (EPS), 7(1), 133-148. http://search.shamaa.org/FullRecord?ID=260026 
Al-Zahrani, S. (2016). The effectiveness of employing electronic brainstorming to provide science teachers with planning skills for active learning. Unpublished MA Thesis, Arab East College, Makkah. https://drgawdat.edutech-portal.net/archives/14832

Al-Zubaidi, N and Bani Khalaf, M (2020). The Effect of Teaching an Educational Unit in Science Based on Design Thinking in Acquisition Physical Concepts for Eighth Grade Students In Light of their Formal Thinking. Educational Journal of Islamic Studies University, 82(6), 1045-1065.

Atenstaedt, R. (2017). Debate \& Analysis Word cloud analysis of the BJGP: 5 years on. British Journal of General Practice, 658(67), 231-232 DOI: https://doi.org/10.3399/bjgp17X690833

Attia, M. (2019). The effectiveness of electronic brain storming styles based on Web 2.0 applications in developing designing skills of interactive learning environment for technology of education student. Unpublished MA thesis, Zagazig University. http://search.shamaa.org/FullRecord?ID=262299

Awwaf, T \& Zaidan, A. (2020). The effects of the interaction between the type of Visual Cue and its display style via digital mobile content on the development of immediate and delayed cognitive achievement among middle school students in the English language curriculum. Journal of Educational and Psychological Sciences. 16 (4), 22 - 51. DOI:https://doi.org/10.26389/AJSRP.G161219

Bromley, K. (2013). Using word clouds in the classroom. The Utah Journal of Literacy. 16(1), . https://milady.cengage.com/blog/using-word-clouds-classroom

Cavender, M and Medico, K. (2018). Beyond Reflection: Using Word Clouds to Support Metacognitive Processes in Preservice Teacher Mathematics Education. Journal of Practitioner Research, 3(2), 1-22. https://doi.org/10.5038/23799951.3.2.1055

Collins, M. (2019). Design Thinking Is a Challenge to Teach — and That's a Good Thing. Retrieved August 30, 2020, from https://www.edsurge.com/news/2019-07-31design-thinking-is-a-challenge-to-teachand-that-s-a-good-thing.

Cook, K \& Bush, S. (2018). Design thinking in integrated STEAM learning: Surveying the landscape and exploring exemplars in elementary grades. School Science and Mathematics, 118(3-4), 93-103. https://doi.org/10.1111/ssm.12268

Debbies, A., Alshshaeir, H \& Rbye, A. (2018). Develop a list of design criteria for a web-based learning environment based on the electronic brainstorming strategy. Journal of Scientific Research in Education, 19(16), 425-436. http://search.shamaa.org/PDF/Articles/EGBahtht/BahthtNo19P16Y2018/bahtht_2018n19-p16_425-436.pdf

Debbis, I. (2019). The relationship of the group pattern (identity information anonymous) in web-based brainstorming strategies to the development of electronic 
writing skills and creative thinking among high school students. Unpublished MA Thesis, Ain Shams University. http://research.asu.edu.eg/handle/123456789/177120

Denoyelles, A \& Foster, B. (2015). Using Word Clouds in Online Discussions to Support Critical Thinking and Engagement. Online Learning, 19(4), 13-24. DOI: $10.24059 /$ olj.v19i4.528

Dosi, C., Rosati, F \& Vignoli, M. (2018). Measuring Design Thinking Mindset. Proceedings of the DESIGN 2018 15th International Design Conference. https://doi.org/10.21278/idc.2018.0493.

Elsbach, K. D., \& Stigliani, I. (2018). Design Thinking and Organizational Culture: A Review and Framework for Future Research. Journal of Management, 44(6),22742306. https://doi.org/10.1177/0149206317744252.

Euro-net, University of Turku, MCPZ d.o.o. ,Fab Lab London \& Erhvervsakademi Sydvest. (2018). Intellectual Output 3 - Toolkit Creative Problem Solving And Design Thinking. Erasmus+.

https://epale.ec.europa.eu/sites/default/files/io3_toolkit_cpsdt_en_final.pdf

Ewina, N. , Luckb, J., Chughc, R \& Jarvisa. (2017). Rethinking Project Management Education: A Humanistic Approach based on Design Thinking. Procedia Computer Science 121, 503-510. DOI: 10.1016/j.procs.2017.11.067

Hammam, A. (2018). The effectiveness of a proposed unit in light of the (STEM) approach to developing design thinking skills in the science subject for students of official language schools. Helwan University. file:///C:/Users/ws/Downloads/58871683.pdf

Hidayanti, I., Rochintaniawati, D \& Agustin, R. (2018). The Effect of Brainstorming on Students' Creative Thinking Skill in Learning. International Program on Science Education, 1(2), 44-48. DOI:10.17509/jsl.v1i2.8738

Hui-Li, A. (2016). Interactive Word Clouds. Project Report, the university of Manchester. http://studentnet.cs.manchester.ac.uk/resources/library/3rd-yearrojects/2016/audrey.leowhui-li.pdf

Jin, Y. (2017). Development of Word Cloud Generator Software Based on Python. Procedia Engineering, 174, 788 - 792. DOI: 10.1016/j.proeng.2017.01.223

Li, Y., Schoenfeld, A., DiSessa, A., Graesser, A., Benson, L., English, L \& Duschl, R. (2019). Design and Design Thinking in STEM Education. Journal for STEM Education Research, 2, 93-104. https://doi.org/10.1007/s41979-019-00020-z.

Le, T \& Lauw, H. (9-15 July 2016). Word Clouds with Latent Variable Analysis for Visual Comparison of Documents. Proceedings of the Twenty-Fifth International Joint Conference on Artificial Intelligence, 2536-2543, New York, USA. Edited by Subbarao Kambhampati, Arizona State University. https://www.ijcai.org/Proceedings/16/Papers/361.pdf 
lemke, D. (2016). Word cloud activities: engaging learners in the online classroom. https://dl.sps.northwestern.edu/blog/2016/01/word-cloud-activities-engaging-learnersin-the-online-classroom/.

Muheisen, A. (2016). The effect of the interaction between two strategies for electronic brainstorming (simultaneous / asynchronous) and the learning style (impulsivity / deliberation) on the development of achievement, technological thinking skills and attitude among students in Gaza. Unpublished PhD thesis. Ain Shams University, Egypt.

Owda, R. (2019). The Impact of Design Management Processes on Decisions Making through Design Thinking. Unpublished MA Thesis, Al-Azhar University. file:///C:/Users/user/Downloads/SSRN-id3417620\%20(1).pdf

Santyasa, I. W., Agustini, K., \& Pratiwi, N. W. E. (2021). Project Based E-Learning and Academic Procrastination of Students in Learning Chemistry. International Journal of Instruction, 14(3), 909-928. https://doi.org/10.29333/iji.2021.14353a

Volkert, D. (2018). Building Reflection with Word Clouds for Online RN to BSN Students. Nursing Education Perspectives, 39(1), 53-54. doi: 10.1097/01.NEP.0000000000000159

Yunis, A. (2017). The effectiveness of using group diussion and brainstorming strategies in developing $e$ - portfolio design skills among the technology teachers in desingn skills among the technoligy teachers in gaza. Unpublished MA thesis, Islamic University of Gaza. https://iugspace.iugaza.edu.ps/handle/20.500.12358/17939.

Zan, N. \& Zan, B. (2015). The Word Cloud Illustration of the Cognitive Structures of Teacher Candidates about Teaching Concept. In Proceedings of Global Learn Berlin 2015: Global Conference on Learning and Technology (pp. 158-166). Berlin, Germany: Association for the Advancement of Computing in Education (AACE). Retrieved November 1, 2020 from https://www.learntechlib.org/primary/p/150859/. 